\title{
POLÍTICAS CURRICULARES, FORMAÇÃO DE PROFESSORESIAS E DIVERSIDADE
}

\author{
CURRICULUM POLICIES, TEACHER TRAINING AND THE DIVERSITY
}

\author{
SANTOS, Maria do Carmo Gonçalo \\ carmo1974@yahoo.com.br
}

Universidade Federal de Pernambuco

SANTIAGO, Maria Eliete

mesantiago@uol.com.br

Universidade Federal de Pernambuco

\begin{abstract}
RESUMO Situada no contexto das políticas públicas para a educação básica, o crescente interesse pela formação de professores/as gera movimentos e tensões em torno do currículo da formação. Este artigo discute sobre as políticas curriculares para a formação de professores/as, com foco na temática da diversidade. Inicialmente tratamos do modelo dos conteúdos culturais e cognitivos e do modelo pedagógico-didático como modelos que sustentam os currículos de formação (SAVIANI, 2009). A partir das políticas neoliberais e do movimento de resistência da categoria, destacamos alguns dos marcos legais principais que norteiam os limites e as condições da formação docente (BRZEZINSKI, 2010). Este trabalho, de natureza qualitativa, porque considera a complexidade do real e a possibilidade de incluir diferentes perspectivas (GUBA; LINCOIN, 2006), foi construído a partir de fonte bibliográfica, com o intuito de ampliar o conhecimento (LAKATOS; MARCONI, 2003). Identificamos a importância de tomar o "chão da escola" e suas demandas como suporte para os currículos de formação docente e para a valorização do magistério; atentando para a diversidade, enquanto caminho para a educação intercultural (CANDAU, 2008).
\end{abstract}

PALAVRAS-CHAVE: Políticas Curriculares. Formação de professores/as. Diversidade.

ABSTRACT Situated in the context of public policy for basic education, the growing interest in teacher training, generates movements and tensions surrounding the education curriculum. This article discusses the curriculum policies for teacher training / as, with focus on the theme of diversity. Initially treat the model of cultural content, cognitive and didactic-pedagogic model as models that support the training curricula (SAVIANI, 2009). From the neo-liberal policies and the resistance movement category, we highlight some of the main legal frameworks that govern the limits and conditions of teacher education (BRZEZINSKI, 2010). This study is 
qualitative, because it considers the complexity of reality and possibility to include different perspectives (GUBA; LINCOIN, 2006), was constructed from bibliographic source, in order to expand knowledge (LAKATOS; MARCONI, 2003). We identify the importance of taking the "ground school" and its demands as support for curricula and teacher training for the enhancement of teaching, paying attention to diversity as a path to intercultural education (CANDAU, 2008).

KEYWORDS: Curriculum Policies. Teacher Training. Diversity.

\section{INTRODUÇÃO}

O crescente interesse por parte das políticas educacionais, das associações e das demandas sociais acerca da formação de professores/as nos instiga a discutir sobre as políticas curriculares da formação de professores/as, com foco para o lugar e o sentido da diversidade nos processos de formação. A inquietação surge do nosso percurso profissional enquanto estudante e professora no Curso de Pedagogia, que nos indica a necessidade de trabalhar com a diversidade, tendo em vista a nossa prática e as demandas dos/as alunos/as para lidar com esta realidade nas escolas.

Entendemos que a formação inicial, sozinha, não dá conta de preparar os/as alunos/as para o exercício da docência, no enfrentamento dos desafios cotidianos da profissão. Entretanto, situamos a formação inicial como aquela que possibilita a revisão de conceitos, a ampliação da visão de mundo do/a aluno/a, a construção coletiva e individual de fios de conhecimentos que entretecem a prática do/a professor/a em início de carreira, a reflexão acerca da identidade docente; além de possibilitar o contato e o diálogo entre teoria e prática, através da entrada no campo de trabalho. Nesse sentido:

\footnotetext{
A formação inicial é um processo circunscrito, com um início, um meio e um fim, que tem por objetivo formar o futuro professor para que este possa começar a ensinar a partir de uma base de conhecimento que the possibilite enfrentar os desafios iniciais da profissão (MIZUKAMI, 1986, p.152).
}

Este tempo de formação introduz o/a aluno/a na complexidade do trabalho docente, a partir de recortes de conhecimentos que vão se articulando no cotidiano 
profissional, sendo enfatizados e até modificados por ele/a ao longo do processo formativo.

O trato com as políticas curriculares para a formação de professores nos convida, primeiro, a conceituar o que compreendemos por currículo. Assim, o definimos, a partir das teorias crítica e pós-crítica de currículo, que superam a concepção das teorias tradicionais, centradas nos processos de ensino e de aprendizagem, sobretudo em relação às técnicas de ensino, ao planejamento e à organização dos conteúdos didáticos. Compreendemos o currículo, portanto, como um território de tensão política, permeado por relações de poder, no qual são produzidos, reproduzidos e ressignificados saberes, Representações Sociais e identidades (LIMA; ZANLORENZI; PINHEIRO, 2011; SILVA, 2007).

Nesse sentido, as políticas curriculares representam as forças do Estado, nem sempre em consonância com as do governo, que emanam das instâncias permanentes da sociedade, em vista da realização de um projeto para a educação. Nos âmbitos macro e micro as políticas curriculares também são tecidas em movimentos de tensão gerados por pensamentos e propostas divergentes. No Brasil, estas tensões são acentuadas a partir da década de noventa, do século passado, devido aos processos de regulação do Estado e, na contracorrente, devido aos movimentos de resistência a essa regulação. Estes processos dizem respeito ao enfraquecimento do Estado, via privatização do público e criação de mecanismos de regulação pelo mercado (FREITAS, 2009; HOFLING, 2001; SHIROMA, 2002).

Situado no panorama social, econômico e cultural das políticas neoliberais e da globalização, o cruzamento de fronteiras chama a temática da diversidade para o diálogo acerca da formação e do currículo, tendo em vista que:

\footnotetext{
Exigências importantes para a formação e o modo de trabalhar dos professores derivam da necessidade de um olhar global sobre o mundo em rede, como para a criação do texto de que se deslocará o currículo, se é que desejamos que essa inteligência prospere. Esta é a nova forma de 'educar para a vida' (GIMENO SACRISTÁN, 2000, p.23).
}

As novas demandas para o currículo problematizam a centralização da formação em conteúdos fechados, presos e desconectados do real. A partir dos fenômenos culturais a temática da diversidade na formação de professores/as e na vivência de práticas pedagógicas promove a inquietação frente às questões de 
gênero, de sexualidade e de etnia. A diversidade é destacada por nós devido à possibilidade de ser assunto omitido no currículo da formação e na realidade das escolas.

As demandas sociais para o trato com a diversidade são muitas, tendo em vista que a escola recebe alunos/as de culturas, etnias, identidades de gênero, orientação sexual, de classes, de religiões e de gerações diversificados; além da diversidade de paradigmas educacionais que sustentam as práticas pedagógicas; como também, a diversidade de ritmos e tempos de aprendizagens dos/as alunos/as. O nosso foco de discussão sobre a formação se inscreve na preocupação com a justiça social, dos grupos discriminados e excluídos das relações, considerados "grupos marginais", porque estão à margem da referência, do centro, dos modelos considerados bons e medida para todas as condições sociais (heterossexual, branca, de classe média), portanto tratamos dos "ex-cêntricos" (LOURO 2003). Desse modo, o repensar do currículo da formação de professores/as, voltado para a multiculturalidade precisa definir sobre qual multiculturalidade está tratando, uma vez que este é um termo polissêmico e complexo.

Em Candau (2008) encontramos duas definições iniciais que nos ajudam a compreender perspectivas distintas do multiculturalismo: o multiculturalismo descritivo, que situa as diferenças sem problematizar as desigualdades, e o multiculturalismo propositivo, que questiona as desigualdades. A segunda perspectiva, do multiculturalismo propositivo, ramifica-se no multiculturalismo assimilacionista, que apesar de considerar a diversidade cultural, toma uma cultura como sua referência; o multiculturalismo diferencialista, que evidencia a identidade de cada cultura, sem estabelecer a relação entre elas; e o interacionista, que busca o diálogo entre as culturas, a interação fundada em trocas de aprendizagens. Para nós esta última perspectiva pode contribuir com as políticas curriculares, por estar voltada para a abertura do conhecimento, dos saberes e das relações, podendo promover uma formação que se aproxime mais da realidade e das necessidades sociais relativas à inclusão, à equidade e ao respeito.

Este artigo busca, na literatura, fios que nos conduzem a tecer a discussão acerca das políticas curriculares de formação, em vista do trabalho com a 
diversidade. Compreendemos que se trata de uma investigação qualitativa, dentre outros fatores, porque lida com o universo de significados, não se limitando apenas aos dados objetivos, concretos, mas estabelecendo o diálogo entre objetividade e subjetividade, em busca de possibilidades de sínteses (CHIZZOTTI, 2001; SANTOS FILHO; GAMBOA, 2000); também, porque busca impedir a marginalização das diferentes vozes, ou seja, não exclui nenhuma perspectiva representativa da realidade (GUBA; LINCOLN, 2006).

A partir dos referenciais teóricos, da base legal e do olhar para a realidade, realizamos uma pesquisa bibliográfica que visa articular os diferentes focos para as políticas curriculares de formação de professores/as. Nesse sentido, a pesquisa bibliográfica busca confrontar diferentes perspectivas acerca do objeto da investigação, em vista de ampliar a discussão, revelando os limites e possibilidades da realidade. "Dessa forma, a pesquisa bibliográfica não é mera repetição do que já foi dito ou escrito sobre certo assunto, mas propicia o exame de um tema sob novo enfoque ou abordagem, chegando a conclusões inovadoras" (LAKATOS; MARCONI 2003, p.183). Procuramos, portanto, não só apresentar a síntese das produções, mas contribuir com outros olhares que possibilitem ampliar e ressignificar o que já foi dito.

Desenvolvemos este trabalho a partir do levantamento bibliográfico, buscando referenciais a partir das categorias: formação de professores/as, políticas curriculares e diversidade. Realizamos os estudos e sua sistematização, através das fichas de documentação bibliográfica, utilizando o critério temático (MINAYO, 2000; SEVERINO, 2000).

Para tanto, iniciamos a discussão com o foco nos contextos e concepções de formação docente, situando os modelos de formação de professores, do início do século XIX presentes até hoje nos currículos. A partir de três marcos legais, eleitos pela sua relevância e abrangência em relação às políticas de formação de professores, situamos os limites e as condições de formação docente, enfatizando as contribuições das associações de professores nas conquistas profissionais da categoria.

Em seguida, trazemos a diversidade, situando-a como uma temática contemporânea que entrecorta o currículo de formação e as práticas pedagógicas e 
docentes, tendo em vista a necessidade de situar a diversidade e a desigualdade de gênero, de orientação sexual e de etnia como conteúdos da formação. Pressupomos que estes conteúdos, geralmente, são subjugados (MOREIRA, 1999), fazem parte dos artefatos perdedores, do currículo fracassado (SILVA, 2008), em desvantagem frente a outros conhecimentos considerados mais importantes, no momento de se pensar e de implementar o currículo, apesar de fazerem parte da vida, das necessidades e da identidade dos sujeitos sociais.

Consideramos, portanto, que as políticas de formação de professores caminham em movimentos de tensão, que geram a dinâmica do currículo, dialogando com uma lógica neoliberal, mas não se furtando a ela, tendo em vista a resistência das associações de professores que proporcionam, sobretudo, muitos dos avanços legais; bem como, acenamos/afirmamos para/as contribuições da literatura crítica e pós-crítica do currículo. Neste contexto, a formação para a diversidade é tratada como uma possibilidade de ampliação do currículo de formação, a partir do modelo didático-pedagógico, que busca a relação entre a formação e a prática, baseada em reflexões críticas e propositivas.

\section{CONTEXTOS E CONCEPÇÕES DE FORMAÇÃO DOCENTE}

$O$ processo de formação docente adquiriu ênfase no século $\mathrm{XIX}$, com a universalização do ensino, a partir da $1^{\text {a }}$ Lei de Instrução Pública, em 1827 , que criou as escolas de primeiras letras, e demandou professores/as formados/as para atuar nestas escolas. As Escolas Normais, criadas no Brasil em 1835, assumiram a formação dos/as professores/as primários/as e, só em 1935, foram criados os primeiros cursos superiores de formação de professores e, especificamente, o Curso de Pedagogia em 1939. Assim, o Ensino Superior assumiu a formação dos professores secundários (TANURI, 2000). Neste contexto são configurados dois modelos de formação: o modelo dos conteúdos culturais-cognitivos, com ênfase na cultura geral e nos conteúdos de ensino, assumido pelo Ensino Superior, e o modelo didático-pedagógico, que buscava a complementação da formação através da dimensão pedagógica, assumido pelas Escolas Normais (SAVIANI, 2009). 
A partir desta dicotomia, estabelecida historicamente, entre conhecimento específico - referendado no modelo dos conteúdos culturais-cognitivos - e conhecimento pedagógico, - apoiado no modelo didático-pedagógico - destacamos a necessária articulação entre ambos no processo de formação de professores/as. Compreendemos que o/a professor/a trabalha situado em um contexto, suas relações são interativas e ele/a não é um/a mero/a transmissor/a de informações desconectadas da realidade e da cultura dos/as alunos/as. A dimensão didáticopedagógica contribui para a contextualização do conhecimento, sua problematização e articulação com a realidade.

$\mathrm{Na}$ formação de professores o cuidado com os processos de ensinagem (ANASTASIOU; ALVES, 2003), com a formação crítica dos/as alunos/as, com a aprendizagem significativa, com a transposição didática, com os tempos de aprendizagem e com as abordagens e técnicas de ensino compõem fundamentos necessários para a formação de professores/as progressistas, uma vez que não se limitam à transmissão do conteúdo da formação.

A devida relação entre conhecimento chamado de específico e conhecimento chamado de pedagógico busca romper com as hierarquias entre as áreas dos conhecimentos e com a dualidade do ensino, com o modelo elitista dos conteúdos culturais cognitivos e o modelo antielitista didático pedagógico. Esta tensão no currículo revela uma incompreensão que dicotomiza o pensar e o fazer, atribuindo aos dois modelos apenas uma face desta relação.

A discussão sobre a formação dos/as professores atualmente, sobretudo no final do século XX, tem sido carro-chefe da Política Educacional (SHEIBE, 2010). Nesse sentido, destacamos marcos legais contemporâneos que incidem sobre as políticas curriculares de formação de professores e revelam as tensões na definição e construção do currículo desta formação; inclusive com concepções assentadas nos modelos acima apresentados.

A Lei 9.394/96, que define diretrizes e bases para a Educação Nacional, se apoia em uma proposta neoliberal de educação, ao instituir, em seu Art. 63, os Institutos Superiores de Educação, com o Curso Normal Superior, como instância formadora de professores/as para atuar na educação Infantil e nos primeiros anos do Ensino Fundamental, retirando dos Cursos de Pedagogia esta competência e 
atribuindo a estes Cursos a formação, apenas, de especialistas. Conforme texto legal:

Art. 62. A formação de docentes para atuar na educação básica far-se-á em nível superior, em curso de licenciatura, de graduação plena, em universidades e institutos superiores de educação, admitida, como formação mínima para o exercício do magistério na educação infantil e nas quatro primeiras séries do ensino fundamental, a oferecida em nível médio, na modalidade Normal. (Regulamento)

Art. 63. Os institutos superiores de educação manterão:

I - cursos formadores de profissionais para a educação básica, inclusive o curso normal superior, destinado à formação de docentes para a educação infantil e para as primeiras séries do ensino fundamental;

Art. 64. A formação de profissionais de educação para administração, planejamento, inspeção, supervisão e orientação educacional para a educação básica, será feita em cursos de graduação em pedagogia ou em nível de pós-graduação, a critério da instituição de ensino, garantida, nesta formação, a base comum nacional (BRASIL, 1996).

Nesta perspectiva, a condição histórica do Curso de Pedagogia, de formar professores/as para a atuação na Educação Infantil e nos anos iniciais do Ensino Fundamental, passa a ser negada, distanciando a preparação dos/as docentes da formação acadêmica, realizada nas Universidades e nas Faculdades de Educação. Em relação à criação dos Institutos Superiores de Educação, Tanuri (2000, p.85) diz:

Por parte de educadores, de instituições de ensino superior e de associações de docentes, embora se reconheça que eles podem ser um avanço nos locais onde inexistem cursos superiores de formação, teme-se um nivelamento por baixo em face da ênfase numa formação eminentemente prática.

Esta é uma proposta vinculada aos interesses privatistas da tendência neoliberal, tendo em vista que a criação dos Institutos Superiores de Educação seria realizada pela iniciativa privada, a fim de atender à demanda, que não é pequena, uma vez que as Universidades têm a prerrogativa para continuar formando o/a pedagogo/a, devido à sua autonomia. A qualidade da formação dos Institutos Superiores de Educação, e também dos Cursos Normais Superiores, é questionada, devido ao aligeiramento, à ênfase na formação prática desvinculada da pesquisa e ao baixo custo dos cursos como uma maneira de nivelar por baixo a formação (SAVIANI, 2009, TANURI, 2000). Para a Associação Nacional pela Formação dos Profissionais da Educação - ANFOPE (2004), a graduação em três anos promove a 
descaracterização profissional do docente, através da redução dos conhecimentos e do tempo de formação.

Em contraposição ao projeto de criação dos Institutos Superiores de Educação e dos Cursos Normal Superior, e superando esta proposta, outro marco legal importante de destacar é a Resolução n.1, de 15 de maio de 2006, que Institui Diretrizes Curriculares Nacionais para o Curso de Graduação em Pedagogia. Estas Diretrizes foram conquistadas a partir do movimento de resistência das associações da categoria, que se manifestou contra a criação dos Institutos Superiores de Educação, produzindo e enviando documento ao Conselho Nacional de Educação. Uma das maiores conquistas deste movimento inscreve-se no Art. $1^{\circ}$, que se refere à definição do Curso de Pedagogia como licenciatura, validando legalmente o que já se configurava na sua tradição histórica; além da afirmação da docência, como base da formação dos/as profissionais da educação, defendida pelas entidades representativas da categoria docente:

\begin{abstract}
Nossas posições históricas - a luta pela formação do educador de caráter sócio-histórico e a concepção da docência como base da formação dos profissionais da educação - têm outro caráter: indicam a necessidade de superação tanto da fragmentação na formação - formar, portanto, o especialista no professor - quanto para a superação da dicotomia - formar o professor e o especialista no educador (ANFOPE, 2004).
\end{abstract}

A defesa, portanto, diz respeito à definição da identidade do Curso de Pedagogia e da identidade do/a profissional docente, que demandam uma orientação curricular articuladora para estes/as profissionais/as. Outra conquista que merece destaque é a validação da sua amplitude na área de formação e de atuação do/a pedagogo/a, situada no Art. $4^{\circ}$, ao destinar a formação do/a licenciado/a para atuar no magistério da Educação Infantil e nos anos iniciais do Ensino Fundamental, no Normal Médio, na Educação Profissional, nas áreas de serviços e de apoio escolar, ou naquelas que o conhecimento pedagógico seja necessário; como também na organização e gestão de sistemas e instituições de ensino. Conforme ressalta Brzezinski (2010, p.765),

Ainda que as históricas reivindicações do movimento não tenham sido atendidas no conjunto normativo das DCNP, os avanços conseguidos por meio de árdua luta, dão contornos a uma outra identidade ao curso e ao 
pedagogo. Em consonância com as DCNP/2006 o pedagogo é professor, é pesquisador, é gestor para atuar em espaços escolares da EB e não escolares, sendo a docência a base da identidade profissional do pedagogo.

São legitimadas, portanto, a formação e atuação do/a pedagogo/a, a partir e para além da docência, considerando, inclusive, a multiplicidade de atividades em campos de atuação diversos, nos quais os/as pedagogos/as trabalham. Ainda tratando das Diretrizes, focalizamos como conquista, o Inciso, I do Art. $6^{\circ}$, que se refere à estrutura do curso de Pedagogia, definindo um núcleo de estudos básicos articulado à diversidade e à multiculturalidade da sociedade brasileira. O princípio da base comum nacional há muito já vinha sendo defendido pela ANFOPE (2004).

A defesa do movimento em relação à organização institucional e curricular dos Cursos de Formação dos Profissionais da Educação, tendo por referência a base comum nacional, orienta-se no sentido de uma estrutura organizativa que favoreça a articulação de todos os componentes curriculares dentro do Projeto Pedagógico de cada Instituição e Curso, de forma a superar as práticas curriculares que tradicionalmente dicotomizam teoria $\mathrm{x}$ prática, pensar $\mathrm{x}$ fazer, trabalho $\mathrm{x}$ estudo, pesquisa $\mathrm{x}$ ensino.

Esta articulação, realizada por meio da definição de um núcleo de estudos básicos, na estrutura curricular do Curso de Pedagogia, busca garantir um referencial de qualidade para as instituições formadoras, sobretudo, no que diz respeito à articulação com a realidade dos processos iniciais de escolarização. Entretanto, o estabelecimento de um núcleo de estudos básicos não "engessa" o currículo, tendo em vista que estas diretrizes também definem um núcleo de aprofundamento e diversificação de estudos na área de atuação profissional, definida pelo Projeto Pedagógico das Instituições, preservando a identidade de cada curso e as necessidades demandadas pelo contexto. Este documento também define um núcleo de estudos integradores que visa à ampliação curricular, através da participação dos/as alunos/as em pesquisa, estudos, monitoria e extensão.

A posição da ANFOPE (2004), materializada no documento enviado ao Conselho Nacional de Educação, para a configuração das Diretrizes Curriculares Nacionais para os Cursos de Pedagogia, defende a formação do/a pedagogo/a, vinculada à proposta de formação das licenciaturas como um todo, definida na Resolução CNE/CP $n^{\circ} 1$, de fevereiro de 2002, que institui Diretrizes Curriculares Nacionais para a Formação de Professores da Educação Básica, em nível superior. 
A referência tomada para a formação é assumir a docência como base articuladora dos cursos, quando diz que "[...] as discussões das Diretrizes da Pedagogia se inserem na discussão das orientações, políticas e Diretrizes da Formação de Professores para a Educação Básica, não podendo, portanto, ser aprovadas fora deste contexto" (ANFOPE, 2004, p.1). A intenção é viabilizar uma política nacional de formação, que englobe os/as profissionais da educação, em todos os níveis e modalidades da formação.

Outro marco legal destacado por nós, que ainda não repercute nas políticas curriculares de formação de professores, mas que já anuncia tensões e intenções no currículo dos cursos de formação de professores/as, é a Portaria Normativa N. ${ }^{\circ} 3$, de 2 de março de 2011, que institui a Prova Nacional de Concurso para o Ingresso na Carreira Docente. A referida Prova visa subsidiar Estados, Distrito Federal e municípios na realização de concursos públicos; conferir parâmetros para a autoavaliação e fornecer subsídios para políticas de formação inicial e continuada. Identificamos como positividade desta medida validar o preceito legal constitucional, situado no Inciso V do Art. 206 e no Inciso I, do artigo 67, da Lei 9.394/96, que define o ingresso na carreira docente, exclusivamente por concurso público e prova de títulos ${ }^{1}$.

Esta medida, que pode vir a estimular a prática do concurso, sobretudo, nos entes federados, onde a realidade da contratação é muito maior do que a da efetivação por meio do concurso público, também anuncia algumas inquietações no que se refere a riscos, que podem acabar interferindo na política curricular dos Cursos de Licenciatura.

Destacamos o risco da criação de mecanismos de seletividade para o processo de profissionalização, que podem vir a dificultar o acesso dos/as alunos/as das classes populares a ingressar na profissão, devido à geração de custos para o processo seletivo; o risco da instrumentalização do saber e da mercantilização da formação, movida a partir de uma lógica que compreenda a formação como preparação para a aprovação, em detrimento da formação para a atuação profissional; inclusive, possibilitando a criação de cursinhos para a prova, a exemplo dos pré-vestibulares e cursos de preparação para o ENEM. Também questionamos

\footnotetext{
${ }^{1}$ Segundo o Inep, a primeira edição da prova será no segundo semestre de 2013. Disponível em: http://portal.inep.gov.br. Acesso em: 25/09/2012.
} 
se esta prova é garantia de qualidade da educação e do trabalho do/a professor/a, já que outros fatores estão envolvidos nesta qualificação.

Dentre alguns destes fatores, podemos citar: o aumento do valor do PIB para a educação; maior investimento na formação docente, sobretudo, em relação às universidades públicas; validação do imperativo legal, relativo à valorização do magistério, conforme o art. 67 da Lei de Diretrizes e Bases; ampliação da oferta pública dos cursos de formação docente e maior articulação entre os entes federados.

Percebemos uma tendência atual de responsabilização e de cobrança em relação aos/às professores/as frente aos resultados educacionais e sociais, pressionando-os/as a qualificar o trabalho e a profissão, através de exames e controle profissional. Esta pressão é evidenciada a partir da regulação do Estado (FREITAS, 2009), sob a forma de avaliações baseadas no mérito e na rendição de contas, mais duras do que leves, porque não são utilizadas apenas para divulgação e análise dos resultados, mas para punir ou premiar as instituições e os sujeitos. Em relação às medidas de controle da profissão, Sheibe (2010, p.985) nos diz:

\footnotetext{
Tais medidas, no entanto, se não totalmente dispensáveis, precisam ser relativizadas frente aos salários nada compensadores, carreiras que não oferecem clareza de percurso, imaginário coletivo desmotivado em relação à profissão, alto índice de abandono da docência e a progressiva queda na procura pelos cursos de licenciatura. Revela-se um cenário que exige assumir prioridades para tornar a ocupação não apenas mais atrativa e valorizada, mas também mais competente para o desenvolvimento de uma educação com qualidade para todos.
}

Ao situarmos o currículo como um campo de tensões e de interesses que provocam construções e ressignificações de práticas, relações, identidades e conhecimentos; e tecermos considerações sobre os contextos e propostas de formação de professores, a partir, inclusive, do imperativo legal, que orienta os currículos de formação docente, discutimos, a seguir, os limites e as condições para a formação de professores, a partir do que nos indica a literatura.

Situamos a formação docente em nível superior como aquela que vai ressignificar conceitos acerca da realidade social, que vai aproximar o/a aluno/a da realidade do trabalho docente, que possibilita a construção de uma identidade profissional, e que tece e entretece uma rede de conhecimentos que ampliam a 
visão de mundo e subsidiam alunos/as nos desafios principais da docência. Reconhecemos, ainda, que "[...] no espaço universitário o estudante de primeira licenciatura vai construindo, no coletivo, sua trajetória profissional e identidade de professor-pesquisador-gestor" (BRZEZINSKI, 2010, p.760).

Reconhecemos os limites para que tal concepção de formação docente se efetive, tendo em vista que "a realidade nos salta aos olhos", mas é necessário destacar que a literatura aponta para condições de formação distantes da necessidade real dos/as alunos/as, com currículos rígidos, que dificultam uma flexibilidade para atender às demandas e à contingência e complexidade da atuação profissional.

A concepção e a forma como se pensa e estrutura parte dos currículos dos cursos de formação de professores/as dificultam o envolvimento de questões profissionais mais próximas da realidade dos/as alunos/as. "Há também uma forte tradição disciplinar no país que impede soluções que envolvam um caráter mais interdisciplinar na formação, vinculado ao campo da prática curricular da escolarização básica" (SHEIBE, 2010, p. 984). Esta tradição de distanciamento entre formação e prática, no entanto, vem sofrendo interferências das correntes progressistas de educação e da mudança de concepções e de práticas pedagógicas de muitas instituições e professores/as que, mesmo com a organização curricular estruturada por disciplinas, procuram aproximar teoria e prática, saberes e sujeitos no percurso de formação inicial dos/as professores/as.

Cunha (2012) trata desta ressignificação, em relação ao currículo, a partir da ruptura com o paradigma da modernidade, materializado na educação através da disciplinarização, da dicotomização entre os conhecimentos, entre corpo e mente, entre subjetividade e objetividade e da organização linear dos conteúdos. Em relação a esta ruptura, ela diz que:

A necessidade de romper com esse paradigma vem mobilizando as reflexões pedagógicas e indicando novas formas de organização dos currículos, de compreensão dos espaços de aprendizagem na sala de aula, de incorporação das narrativas de vida como elemento de ancoragem dos novos saberes, nas alterações da relação teoria-prática, do ensinopesquisa, cultura-ciência, para nomear algumas dimensões fundamentais (CUNHA, 2012, p.3). 
A mudança de paradigmas gera, assim, uma maior articulação entre campos, sujeitos, saberes e vivências consideradas polos opostos na formação docente, que passam a ser compreendidos e tratados como processuais, dinâmicos, complementares e dialógicos. Nessa perspectiva, as Diretrizes curriculares para o Curso de Pedagogia, definem, em seu artigo $3^{\circ}$, que

O estudante de Pedagogia trabalhará com um repertório de informações e habilidades composto por pluralidade de conhecimentos teóricos e práticos, cuja consolidação será proporcionada no exercício da profissão fundamentando-se em princípios de interdisciplinaridade, contextualização, democratização, pertinência e relevância social, ética e sensibilidade afetiva e estética (BRASIL, 2006).

Esta articulação entre teoria e prática indica que os cursos de Pedagogia precisam dar conta de uma diversidade de conhecimentos problematizados pela realidade do exercício docente; e o documento é balizador desta articulação.

Dentre as várias e oportunas possibilidades que podemos destacar para discutir sobre o currículo da formação de professores, situamos: escutar as demandas; perceber a relevância do trabalho docente no currículo da formação; repensar as condições de trabalho que envolvem a carreira e a formação docente e equilibrar e articular os eixos da formação docente (ensino-pesquisa-extensão).

Segundo Saviani (2009, p.151), a dissociação de aspectos da formação foi causada "[...] por um processo de abstração; para recuperar a indissociabilidade será necessário considerar o ato docente como fenômeno concreto, isto é tal como ele se dá efetivamente no interior das escolas". Nesse sentido, a formação de professores/as, assentada em paradigmas conservadores de educação, limitada aos conteúdos culturais cognitivos, distancia-se desta articulação com o real. Saviani (ibid.) propõe eleger o livro didático da educação básica como ponto de partida para repensar os currículos dos cursos de licenciaturas, pois, para este teórico, é uma forma de provocar o estudo, a leitura e análise crítica destes conteúdos e das teorias pedagógicas estudadas ao longo do curso, além de aproximar os/as alunos/as das realidades vivenciadas pelas escolas.

Ao compreender a proposta de Saviani como uma de muitas possibilidades para tomarmos como ponto de partida, parece-nos que escutar as demandas é uma sugestão recorrente entre os/as autores que abordam o currículo da formação de 
professores (FORONI, 2004; MOREIRA, 1999; SAVIANI, 2009; SALES, 2012), no sentido deste currículo dialogar com a realidade para a qual está formando o/a aluno/a.

Importante situar o trabalho de Sales (2012) que trata da docência no Ensino Superior nas Representações Sociais dos Estudantes, quando revela que os estudantes tomam os/as professores/as dos cursos de formação como referência, mostrando a relevância do trabalho docente no currículo da formação. A autora também revela que, no âmbito das faculdades privadas, as iniciativas institucionais de formação dos/as professores/as formadores/as são pontuais e que os investimentos em educação ocorrem de forma individual. Estes achados anunciam que é necessário pensar o currículo também a partir da formação dos/as professores/as formadores/as.

A literatura aponta, ainda, a importância de serem repensadas as condições de trabalho que envolvem a carreira e a formação docente, no que se refere a tornar a profissão atrativa para profissionais comprometidos/as e que tenham interesse em investir na profissão (BRZEZINSKI, 2010; SAVIANI, 2009). O movimento da profissionalização e formação docente não é um movimento de mão única; necessita de investimentos públicos e também do/a profissional, que disponibiliza tempo, dinheiro, energia e interesse no processo de formação.

Outro ponto que destacamos, em relação ao currículo de formação de professores/as, diz respeito à necessidade de equilíbrio e diálogo entre os eixos da formação, ou seja, o ensino, a pesquisa e a extensão, com foco para a docência como base da formação, em vista do cuidado em não supervalorizar um eixo em detrimento de outro.

E, por fim, registramos a importância de que os currículos contemplem a diversidade cultural (FORONI, 2004), que dialoguem com e produzam o diálogo entre as diferentes culturas, buscando a superação das desigualdades. Segundo o inciso X, do Art. $5^{\circ}$, das Diretrizes Curriculares para o Curso de Pedagogia, o egresso deverá estar apto a: "demonstrar consciência da diversidade, respeitando as diferenças de natureza ambiental-ecológica, étnico-racial, de gênero, faixas geracionais, classes sociais, religiões, necessidades especiais, escolhas sexuais, entre outras" (BRASIL, 2006). 
Vemos este ponto como uma importante temática de reflexão para as políticas curriculares voltadas para a formação docente, uma vez que a abertura e interesse dos/as professores/as para realizar uma prática pedagógica menos excludente necessitam de conhecimentos que os/as levem a refletir sobre os próprios preconceitos engendrados pela nossa cultura. Podemos afirmar, ainda, que a complexidade do conceito de multiculturalidade demanda uma aproximação teórico-prática do/a professor/a em relação às várias correntes de pensamento, a fim de situá-lo/a em suas definições e escolhas. Compreendemos, junto com Freira (2009) e com Souza (2009), que o trabalho multicultural exige um esforço políticopedagógico, que não se realiza de forma espontânea.

\section{FORMAÇÃO DOCENTE E CURRÍCULO PARA O TRATO COM A DIVERSIDADE}

A formação docente para o trato com a diversidade indica uma preocupação com os processos de exclusão-inclusão que marcaram e marcam a nossa história de país colonizado, de mulheres, índios/as, negros/as e crianças lesados/as e subjugados/as, de homossexuais discriminados/as e violentados/as. Esta realidade também atravessa os muros das escolas, tendo em vista que é constituída por sujeitos sociais reais, oriundos de vivências de desigualdade, de desrespeito e de negação.

Diante deste contexto, a presença, a intencionalidade e o trato com a diversidade nos currículos de formação são questões pertinentes e inadiáveis, a partir da compreensão apresentada anteriormente, de que a formação possibilita um leque de conhecimentos e de saberes que contribuem para a ressignificação de visões de mundo, que nos ajudam a acessar novos conceitos e a repensar sobre as nossas práticas.

Nesse sentido, o lugar e o propósito em relação à temática da diversidade ganham força no currículo da formação de professores/as, ultrapassando a fronteira que separa os conhecimentos considerados mais importantes dos conhecimentos considerados marginais, subjugados, fracassados (MOREIRA, 1999; SILVA, 2008). Interessante destacar que a questão da diversidade é inerente às temáticas centrais da formação, na relação professor/a-aluno/a, nos processos de ensino e 
aprendizagem, nas concepções e práticas de avaliação, que de forma explícita ou implícita, consciente ou inconsciente, acabam sendo utilizadas como referentes de muitas práticas, geralmente, de exclusão (CARVALHO, 2009; CARVALHO FREIRE, 2002).

A diversidade por nós evidenciada diz respeito à possibilidade de múltiplas expressões, identidades e compreensões de gênero, de sexualidade e de etnia, que configuram a multiculturalidade, sobretudo em relação à interculturalidade (CANDAU, 2008). Interculturalidade, não apenas a partir da consideração da diversidade, mas da relação entre as culturas, relação de aprendizagens, de partilhas e de reflexões acerca dos seus limites; interculturalidade como compreensão da especificidade e da diversidade de culturas em uma mesma cultura. Diversidade situada no debate sobre justiça social, em relação àqueles e àquelas que sofrem com a desigualdade e lutam pelo respeito, pelo trato diferenciado, em vista da equidade.

Para Moreira (1999), os últimos vinte anos do século passado marcam a preocupação da educação com a formação docente e, também, com a reformulação curricular dos cursos de formação de professores/as. Ele analisa que pouco se tem avançado no campo das práticas, embora reconheça os avanços teóricos, dizendo que predomina a estabilidade em detrimento da mudança. E, ainda, chama a atenção para a relevância das discussões sobre a multiculturalidade no currículo da formação, tendo em vista a emergência da temática na contemporaneidade, pois

[...] mesmo que as reflexões sobre currículo e sobre formação de professores desconsiderem a multiculturalidade, ela estará presente nos sistemas escolares, nas escolas, nas salas de aula, nas experiências da comunidade escolar, afetando inevitavelmente as ações e as interações de seus diferentes sujeitos (MOREIRA, 1999, p.85).

Neste sentido, a multiculturalidade é realidade presente nos espaços sociais e não podemos ignorá-la; ao contrário, os espaços educativos, dentre eles, o espaço escolar, tem a possibilidade de aproximar e valorizar as diversas culturas. Algumas questões nos ajudam a refletir:

Como fazer emergir em nós um professor multicultural que dê conta das referências culturais múltiplas? Como rever práticas educativas construídas, 
alicerçadas e tão inseridas num universo cultural utilitarista homogeneizador que dêem conta de tal desafio? (FORONI, 2004, p.114).

Situamos assim a importância do trabalho do/a professor/a, sem a intenção de supervalorizá-lo e relativizar a realidade social de desigualdades. Estamos, no entanto, dando relevo à necessidade dos currículos de formação de professores/as observarem esta realidade multicultural e inserirem as questões da diversidade, da interculturalidade, da identidade, das relações de poder nos seus conteúdos e práticas.

Nesse sentido, a formação de professores/as para atuar na Educação Básica, subsidiada em vivências teóricas e práticas, pode vir a contribuir com práticas docentes e pedagógicas transformadoras. Situamos a escola enquanto espaço de produção e de ressignificação de identidades, capaz de fortalecer culturas, práticas e relações, além de contribuir para rever estereótipos, preconceitos e discriminações construídas pela nossa cultura.

Ao tratarmos, neste artigo, das políticas curriculares na formação de professores/as, com foco para a diversidade, vimos que o modelo cultural-cognitivo de formação não consegue alcançar estas discussões porque se centra nos conteúdos considerados mais importantes na estrutura hierárquica das disciplinas. Vimos, ainda, que este modelo trata os conteúdos de forma descontextualizada e "neutra", não problematizando a realidade social, tampouco considerando a subjetividade dos sujeitos envolvidos no processo educacional. Consideramos, portanto, a possibilidade do modelo pedagógico-didático ampliar esta compreensão e aproximar-se das temáticas da diversidade, tomando as vivências reais dos/as alunos/as como referências para a formação e para o diálogo com os conteúdos considerados específicos.

Em relação aos marcos legais contemporâneos que norteiam as políticas curriculares da formação (Lei de Diretrizes e Bases, Diretrizes Curriculares, Prova Nacional de Concurso), destacados por nós, situamos a presença da tendência neoliberal como geradora de tensões, frente aos movimentos que consideram e valorizam a presença das discussões sobre a diversidade como questão emergente no currículo da formação. 
Em decorrência da ideologia da competitividade, do discurso da produtividade, da centralidade na economia em detrimento das finalidades sociais, que norteiam as políticas neoliberais, compreendemos que o cuidado com a formação humana, com a alteridade e com os valores de respeito e de igualdade fica ameaçado pelos interesses neoliberais. Nesse sentido, destacamos a força dos movimentos de resistência, implementados pelas associações de professores/as que buscam uma formação assentada na docência, referendada em responsabilidade social. A nossa realidade de desigualdades demanda

[...] a formação de pedagogos cada vez mais sensíveis à solicitação do real, mas não limitados a ele, profissionais que possam cada vez mais, em um processo de trabalho intelectual, criar novas alternativas às exigências de formação e de organização da escola básica, produzindo e construindo novos conhecimentos, que contribuam para a formação e emancipação humanas de nossos adultos, nossa infância e juventude (ANFOPE, 2004, p.3).

A orientação das políticas curriculares passa a ter outro norte. Os conteúdos e o trato destes conteúdos da formação seguem outro caminho, possibilitando a presença e a vivência de questões de gênero, de etnia e de sexualidade nos cursos de licenciatura. Entretanto, esta formação, assentada em uma proposta progressista de educação, que dialoga com os processos de humanização, também tende a ser descaracterizada pelos desafios em relação à valorização profissional e ao investimento público em formação. Para Saviani (2009, p.153),

[...] a questão da formação de professores não pode ser dissociada do problema das condições de trabalho que envolvem a carreira docente, em cujo âmbito devem ser equacionadas as questões do salário e da jornada de trabalho. Com efeito, as condições precárias de trabalho não apenas neutralizam a ação dos professores, mesmo que fossem bem formados. Tais condições dificultam também uma boa formação, pois operam como fator de desestímulo à procura pelos cursos de formação docente e à dedicação aos estudos.

Ao tratarmos dos limites que comprometem as políticas curriculares de formação de professores/as não as definimos como impeditivo à qualificação docente, mas as situamos no contexto real da profissionalização do magistério, uma vez que a formação é um dos seus eixos. 
Também situamos/anunciamos neste artigo os caminhos para a formação apontados pela literatura, que dizem respeito à articulação entre formação e atuação, tomando o chão da escola como ponto de partida e de chegada. Abordamos a relevância do trabalho docente do/a professor/a-formador/a, que necessita da iniciativa da formação e da pesquisa, também por parte da instituição, uma vez que estas ações são muito mais individuais do que institucionais. Discutimos a revisão da valorização do magistério, em relação ao acesso, formação e carreira, à articulação entre ensino-pesquisa-extensão no processo de formação, assumindo a docência como base. E, finalmente, refletimos sobre a ênfase na formação para o trato com a diversidade, a partir da inserção da temática e da vivência intercultural nos currículos dos cursos de formação.

Em síntese, o artigo tratou das políticas curriculares para a formação docente, com foco na diversidade, entendendo que o campo destas políticas gera tensões e intenções, avanços e recuos, em nível macro e micro, uma vez que concepções, propostas e interesses estão em disputa neste espaço.

Diante deste contexto, conquistas têm sido alcançadas pela resistência das associações de professores/as, que conseguem, a partir de uma concepção de docência como base da formação, situar as práticas pedagógicas como norte para o currículo da formação docente. No interior desta proposta destacamos a importância da formação e das práticas pedagógicas considerarem e valorizarem a diversidade cultural como possibilidade para a realização de uma educação intercultural. Para nós, a educação intercultural ultrapassa a inserção de temáticas no currículo de formação, buscando também a vivência destas temáticas no cotidiano dos cursos de formação, com o objetivo de atribuir sentido, vida e movimento a este currículo.

As políticas curriculares de formação para o trato com a diversidade podem alcançar a educação intercultural, a partir da compreensão, afirmação e superação dos preconceitos arraigados em nossa cultura patriarcal, sexista, racista que fazem parte das nossas práticas sociais, inclusive, da nossa prática docente.

A fim de continuar investigando sobre as políticas curriculares de formação de professores/as, atentando para a questão da diversidade, pensamos que ouvir os sujeitos da prática pedagógica (gestores/as, professores/as e alunos/as) pode ajudar a ampliar, refutar ou referendar as discussões aqui tecidas, com o intuito de 
contribuir com o processo de formação docente e com práticas docentes mais equitativas e menos desumanas no cotidiano das escolas.

\section{MARIA DO CARMO GONÇALO SANTOS}

Doutoranda pela Universidade Federal de Pernambuco (UFPE), no Núcleo de Formação de Professores e Prática Pedagógica. Professora das Licenciaturas em Pedagogia, Filosofia e História na Faculdade de Filosofia, Ciências e Letras de Caruaru (FAFICA/PE).

\section{MARIA ELIETE SANTIAGO}

Professora Titular do Centro de Educação da Universidade Federal de Pernambuco (UFPE), no Núcleo de Formação de Professores e Prática Pedagógica. Coordenadora da Cátedra Paulo Freire da UFPE.

\section{REFERÊNCIAS}

ANASTASIOU, Léa das Graças Camargos; ALVES, Leonir Pessate (orgs.). Processos de ensinagem na universidade: pressupostos para as estratégias de trabalho em aula. Joinville, SC: UNIVILLE, 2003.

ASSOCIAÇÃO NACIONAL PELA FORMAÇÃO DOS PROFISSIONAIS DA EDUCAÇÃO. A Definição das diretrizes para o curso de pedagogia. 2004.

BRASIL. Lei n. 9.394, de 20 de dezembro de 1996. Estabelece as diretrizes e bases da educação nacional. Diário Oficial da União, Brasília, DF, 23 dez. 1996.

BRASIL. Ministério da Educação. Conselho Nacional de Educação. Parecer CNE/CP n. 9, de 8 de maio de 2001. Diretrizes Curriculares Nacionais para a Formação de Professores da Educação Básica, em nível superior, Curso de Licenciatura, de graduação plena. Diário Oficial da União, Brasília, DF, 18 jan. 2002, seção 1, p. 31.

BRASIL. Ministério da Educação. Conselho Nacional de Educação. Resolução CNE/CP n ${ }^{\circ} 1$, de 15 de maio de 2006. Institui Diretrizes Curriculares Nacionais para - Curso de Graduação em Pedagogia, licenciatura. Diário Oficial da União, Brasília, DF, Seção 1, p. 11, 15 de maio de 2006.

BRASIL. Ministério da Educação. Portaria Normativa N.3, de 2 de março de 2011. Institui a prova nacional de concurso para o ingresso na carreira docente. Diário Oficial da União, Brasília, DF, Seção 1, p. 9, 3 de março de 2011.

BRZEZINSKI, Iria. Convergências e tensões na formulação das atuais políticas para a formação de professores no Brasil: entre o arcabouço normativo e o respeito às culturas e às formas de vida. In: DALBEN, Ângela Imaculada Loureiro de Freitas et 
al. Convergências e tensões no campo da formação e do trabalho docente. Belo Horizonte: Autêntica, 2010. p. 750-769. (Didática e prática de ensino).

CANDAU, Vera Maria. Multiculturalismo e educação: desafios para a prática pedagógica. In: ; CANDAU; Vera Maria (orgs.). Multiculturalismo: diferenças culturais e práticas pedagógicas. 2. ed. Petrópolis, RJ: Vozes, 2008. p.13-37.

CARVALHO FREIRE, Eleta de. As Representações Sociais de gênero das professoras de História do ensino fundamental da rede municipal de recife no cotidiano da sala de aula. Recife, 2002. 178 f.. Dissertação (Mestrado em Educação) - Universidade Federal de Pernambuco.

CARVALHO, Marília Pinto de. Avaliação escolar, gênero e raça. Campinas, SP: Papirus, 2009.

CHIZZOTTI, Antonio. Pesquisa em ciências humanas e sociais. 5.ed. São Paulo: Cortez, 2001.

CUNHA, Maria Isabel da. Pesquisa, inovações e formação docente. Palestra Proferida no Auditório da FAFIRE, Recife, 09 de agosto de 2012.

FORONI, Yvone M. Dálessio. Encontro das paralelas: repensando a questão de procedimentos de ensino na multiculturalidade e na educação especial. In: CARLINI, Alda Luiza et al.; SCARPATO, Marta (Org). Os procedimentos de ensino fazem a aula acontecer. São Paulo: Editora Avercamp, 2004. p.113-122. (Coleção didática na prática).

FREIRE, Paulo. Pedagogia da Esperança: um reencontro com a pedagogia do oprimido. 16. ed. São Paulo: Paz e Terra, 2009.

FREITAS, Luiz Carlos de. et AL. Avaliação Educacional: caminhando pela contramão. 2. Ed. Petrópolis, RJ: Vozes, 2009. (Coleção Fronteiras Educacionais).

GIMENO SACRISTÁN, J. O currículo: uma reflexão sobre a prática. Tradução Ernani F. da Fonseca Rosa. 3.ed. Porto Alegre: Artmed, 2000.

GUBA, Egon G.; LINCOIN; Yvonna S. Controvérsias paradigmáticas, contradições e confluências emergentes. In.: DENZIN, Norman K.; LINCOIN, Yvonna S. O planejamento da pesquisa qualitativa: teorias e abordagens. Tradução Sandra Regina Netz. Porto Alegre: Artmed, 2006. p.169-192.

HÖFLING, Eloisa de Mattos. Estado e Políticas (públicas) sociais. Cadernos Cedes, ano XXI, n. 55, p.30-41, novembro/2001.

LAKATOS, Eva Maria; MARCONI, Marina de Andrade. Fundamentos de metodologia científica. 5. ed. São Paulo: Atlas, 2003. 
LIMA, Michelle Fernandes; ZANLORENZI, Claudia Maria Petchak; PINHEIRO, Luciana Ribeiro. A função do currículo no contexto escolar. Curitiba: Ibpex, 2011.

LOURO, Guacira Lopes. Currículo, gênero e sexualidade: o "normal", o "diferente" e o "excêntrico". In.: ; FELIPE, Jane; GOELLNER, Silvana Vilodre. Corpo, gênero e sexualidade: um debate contemporâneo na educação. 2. ed. Petrópolis, RJ: Vozes, 2003. p. 41-52.

MINAYO, Maria Cecília. O desafio do conhecimento: pesquisa qualitativa em saúde. 7. ed, São Paulo: Hucitec; Rio de Janeiro: Abrasco, 2000.

MIZUKAMI, Maria da Graça Nicoletti. Ensino: as abordagens do processo. São Paulo: EPU, 1986. (Temas básicos de educação e ensino).

MOREIRA, Antonio Flavio Barbosa. Multiculturalismo, currículo e formação de professores. In: (org.) Currículo: Políticas e práticas. Campinas, SP: Papirus, 1999. p. 81-98. (Coleção Magistério: Formação e Trabalho Pedagógico).

SALES, Mônica Patrícia da Silva. Docência no Ensino Superior nas Representações Sociais de Estudantes. Universidade Federal de Pernambuco. Centro de Educação. Recife. 2012. 177p. Dissertação de Mestrado.

SANTOS FILHO, José Camilo dos; GAMBOA, Silvio Sánches. Pesquisa educacional: quantidade-qualidade. 3. ed. São Paulo, Cortez, 2000. (Coleção Questões da Nossa Época; v. 42).

SAVIANI, Dermeval. Formação de professores: aspectos históricos e teóricos do problema no contexto brasileiro. Revista Brasileira de Educação, v. 14, n. 40, p. 143-155, jan./abr. 2009.

SEVERINO, Antônio Joaquim. Metodologia do trabalho científico. 21. ed. São Paulo: Cortez, 2000.

SHEIBE, Leda. Valorização e formação dos professores para a educação básica: questões desafiadoras para um novo Plano Nacional de Educação. Educação e Sociedade, Campinas, v. 31, n.112, p.981-1000, jul./set. 2010.

SHIROMA, Eneida Oto; MORAIS, Maria Célia M.; EVANGELSTA, Olinda. Política educacional. 2. ed. Rio de Janeiro: DP\&A, 2002.

SILVA, Tomaz Tadeu da. Documentos de identidade: uma introdução às teorias do currículo. 2. ed. Belo Horizonte: Autêntica, 2007.

In: GOODSON, Ivor F.Currículo: teoria e história. Tradução Atílio Brunetta. 8. ed. Petrópolis, RJ: Vozes, 2008. (Ciências sociais da educação). 
ATOS DE PESQUISA EM EDUCAÇÃO - PPGE/ME

ISSN 1809-0354 v. 8, n. 2, p.568-591, mai./ago. 2013

DOI http://dx.doi.org/10.7867/1809-0354.2013v8n2p568-591

SOUZA, João Francisco de. Prática pedagógica e formação de professores. In: BATISTA NETO, J.; Autor. (orgs.). Prática pedagógica e formação de professores. Recife: Ed. Universitária da UFPE, 2009.

TANURI, Leonor. História da formação de professores. Revista brasileira de educação. ANPED Campinas, n. 14, p. 61-88, mai./ago., 2000. 